\section{BMJ Open Respiratory Research}

\title{
Gait speed is associated with death or readmission among patients surviving acute hypercapnic respiratory failure
}

\author{
Gatete Karege, ${ }^{1}$ Dina Zekry, ${ }^{2}$ Gilles Allali, ${ }^{3,4}$ Dan Adler, ${ }^{5}$ Christophe Marti ${ }^{1}$
}

\begin{abstract}
To cite: Karege G, Zekry D, Allali G, et al. Gait speed is associated with death or readmission among patients surviving acute hypercapnic respiratory failure. BMJ Open Resp Res 2020;7:e000542. doi:10.1136/ bmjresp-2019-000542
\end{abstract}

\section{DA and CM contributed equally.}

The present work was presented as an abstract at the Swiss Society of General Internal Medicine Congress in June 2019.

Received 1 December 2019 Revised 19 May 2020 Accepted 29 May 2020

Check for updates

\section{(C) Author(s) (or their} employer(s)) 2020. Re-use permitted under CC BY-NC. No commercial re-use. See rights and permissions. Published by BMJ.

${ }^{1}$ Division of General Internal Medicine, Geneva University Hospitals, Geneva, Switzerland

${ }^{2}$ Division of Internal Medicine for the Aged, Geneva

University Hospitals, Geneva, Switzerland

${ }^{3}$ Division of Neurology, Geneva University Hospitals, Geneve, Switzerland

${ }^{4}$ Division of Neurology,

Yeshiva University, New York, New York, USA

${ }^{5}$ Division of Pulmonary

Diseases, Geneva University

Hospitals, Geneva,

Switzerland

Correspondence to

Dr Gatete Karege;

gatete.karege@hcuge.ch

\section{ABSTRACT}

Objectives Death or hospital readmission are frequent among patients surviving acute hypercapnic respiratory failure (AHRF). Severity scores are not valid to predict death or readmission after AHRF. Gait speed, a simple functional parameter, has been associated with hospital admission and death in the general population. The purpose of this study is to highlight an association between gait speed at hospital discharge and death or readmission among AHRF survivors.

Design Secondary analysis of a prospective cohort study. Settings Single Swiss tertiary hospital, pulmonary division.

Participants Patients were prospectively recruited to form a cohort of patients surviving AHRF in the intensive care unit between January 2012 and May 2015.

Outcome measure Gait speed was derived from a 6 min walking test (6MWT) before hospital discharge. All predictive variables were prospectively collected. Death or hospital readmission were recorded for 6 months. Univariate and multivariate analyses were performed to evaluate the association between predictive variables and death or hospital readmission.

Results 71 patients performed a 6MWT. 34/71 (48\%) patients died or were readmitted to the hospital during the observation period. Median gait speed was 0.7 (IQR $0.3-1.0) \mathrm{m} / \mathrm{s}$. At 6 months, $66 \%$ (25/38) of slow walkers (gait speed $<0.7 \mathrm{~m} / \mathrm{s}$ ) and $27 \%(9 / 33)$ of non-slow walkers died or were readmitted to the hospital $(p=0.002)$. In univariate analysis, gait speed was associated with death or readmission ( $\mathrm{HR} 0.41 ; 95 \% \mathrm{Cl} 0.19$ to $0.90, \mathrm{p}=0.025$ ). In a multivariate model adjusted for age, gender, body mass index, forced expired volume, heart failure and home mechanical ventilation, gait speed remained the only variable associated with death or readmission (multivariate HR: $0.35 ; 95 \% \mathrm{Cl} 0.14$ to $0.88, p=0.025$ ).

Conclusion This study suggests that a simple functional parameter such as gait speed is associated with death or hospital readmission in patients surviving AHRF.

Trial registration number NCT02111876.

\section{INTRODUCTION}

Acute hypercapnic respiratory failure (AHRF) is a turning point in the course of chronic obstructive pulmonary disease (COPD) and other causes of chronic respiratory failure. Non-invasive ventilation (NIV) reduces the intubation rate and in-hospital

Key messages
What is the key question?
Could gait speed be associated with death or read-
mission among patients surviving acute hypercapnic
respiratory failure (AHRF)?
What is the bottom line?
Gait speed, measured on hospital discharge in pa-
tients surviving AHRF, is associated with death or
readmission at 6 months.
Why read on?
This is one of the first study to demonstrate an as-
sociation between gait speed and death or hospital
readmission among patients surviving AHRF. Given
the poor prognosis after an index episode of AHRF,
improving risk stratification might contribute to bet-
ter individualise therapeutic interventions and iden-
tify patients who would benefit from rehabilitation or
integrated care programmes.

Strengths and limitations of this study

- This study is based on a prospective cohort of patient recruited after an acute hypercapnic respiratory failure in the intensive care unit.

- Gait speed assessment is standardised and easily reproducible and may provide important prognostic information.

- The primary outcome includes death and readmission, two clinically relevant outcomes.

- The main limitation is the size of the sample limiting the precision of the strength of association estimates.

mortality in patients with AHRF, and allows to treat patients with advanced disease including those who decline intubation. ${ }^{1-5}$ However, longer term prognosis after an index episode of AHRF remains poor with a median survival of less than 4 years. ${ }^{67}$ In a prospective cohort of patients with COPD surviving AHRF, one half of patients died at 1 year and twothirds experienced another life-threatening event. ${ }^{8}$ After a second admission for AHRF, patients typically enter a deteriorating health 
trajectory with more frequent and severe exacerbations until death. ${ }^{5}$ Therefore, prognostic assessment of those surviving AHRF is of importance to provide specific interventions or discuss advanced care planning.

Traditional scores combining pulmonary function, the history of past exacerbations and comorbidities, such as Body-mass index, airflow Obstruction, Dyspnea, and Exercise Index and Comorbidity, age, Obstruction, Dyspnea, and previous severe EXacerbations, have been validated to compute outcome of stable patients with COPD or those experiencing an exacerbation but have not been tested in a specific population of patients surviving AHRF in the intensive care unit (ICU) ${ }^{9}{ }^{10}$ Comorbidities are significantly associated with a longer length of stay but poorly predict 3 months death or readmission among AHRF survivors. ${ }^{11}$ Therefore, simple predictors of death or hospital readmission in this setting are required.

Frailty is a common problem among patients with chronic respiratory insufficiency and sarcopenia affects up to $15 \%$ of patients with COPD. ${ }^{12}{ }^{13}$ Gait speed is a key marker of frailty as it integrates multisystem function including sensory perception, motor function, coordination, nutritional status, cognitive status and cardiac-respiratory function. Gait speed has been shown to predict mortality in elderly patients with significant increments per $0.1 \mathrm{~m} / \mathrm{s} .{ }^{14}$ Among patients with respiratory conditions, such as idiopathic pulmonary fibrosis, gait speed better predicts mortality than gender, age or a clinical tool combining those variables with pulmonary function tests. ${ }^{15}$ However, gait speed has not been studied to predict mortality or hospital readmission in patients with AHRF.

We hypothesised that gait speed measured prospectively on hospital discharge is associated with death or hospital readmission after an admission in the ICU for AHRF.

\section{METHODS}

\section{Study design}

We performed a secondary analysis of a single-centre prospective cohort recruited at the Geneva University Hospitals between January 2012 and May 2015. The detailed methods and main results of this cohort have been detailed elsewhere. ${ }^{11}$ Briefly, consecutive patients surviving AHRF were recruited at ICU discharge. AHRF was defined by a $\mathrm{pH}<7.35$ with an arterial carbon dioxide tension $\left(\mathrm{PaCO}_{2}\right)$ of $>6.3 \mathrm{kPa}$ and the need for invasive or non-invasive ventilation (NIV). Exclusion criteria were: age younger than 18 years old, neuromuscular disease, pregnancy, iatrogenic respiratory failure, life expectancy of less than 3 months, confusion despite total/partial blood gas normalisation, or major psychiatric disease, absence of $6 \mathrm{~min}$ walking test. Demographic data were collected at ICU discharge. Pulmonary function tests and echocardiography were systematically performed before hospital discharge, usually between 7 and 15 days after ICU discharge. Heart failure was diagnosed based on history and physical examination and evidence of systolic (left ventricular ejection fraction $<55 \%$ ) or diastolic dysfunction. Gait speed in $(\mathrm{m} / \mathrm{s})$ was computed using a 6 min walking test performed at hospital discharge. Mean gait speed was obtained by dividing the $6 \mathrm{~min}$ distance walk in metres by time in seconds. The primary outcome combined death or hospital readmission. Hospital readmission or death were prospectively recorded at regular intervals for 6 months by reviewing medical records or through telephone calls to the patients or to family members.

\section{Participant and public involvement}

All patients provided written informed consent. Patients had no involvement in the design, the conduct of the study and the writing of the manuscript.

\section{Statistical analysis}

Descriptive statistics are reported as counts and percentages for categorical data and means and SD or the median and IQR for continuous variables. We constructed a Kaplan-Meier cumulative-event curve for hospital-free survival. Surviving patients were defined as patients alive without hospital readmission. The data were censored at 6 months after ICU discharge. Log-rank test was used to compare the curves in two groups (categorical classification of slow walkers vs non-slow walkers). Slow walkers were defined as patients with gait speed inferior to the observed median in our cohort expressed in metre/ second rounded to the tenth. To evaluate the strength of association between gait speed and our primary outcome, a regression model (Cox proportional hazard model) was built using gait speed, treated as a continuous variable. Univariate and multivariate analyses were computed including age, gender and prespecified risk factors for readmission such as body mass index (BMI), forced expiratory volume in one second $\left(\mathrm{FEV}_{1}\right.$; treated as continuous variables), home mechanical ventilation (HMV) and heart failure. A p value of $<0.05$ was considered statistically significant. HRs are given with $95 \%$ CIs. All analyses were performed using STATA V.14.2 (Statacorp).

\section{RESULTS}

Of the 78 patients included in the original cohort, 71 $(85 \%)$ had a 6 MWT recorded in our database. Characteristics of the study population are provided in table 1 . Median gait speed was $0.7 \mathrm{~m} / \mathrm{s}$ (IQR $0.3-1.0 \mathrm{~m} / \mathrm{s}$ ). Thirty-four patients $(48 \%)$ died or were readmitted to the hospital during the observation period of 6 months. Of those, $25(74 \%)$ were slow walkers, as defined by a gait speed of less than $0.7 \mathrm{~m} / \mathrm{s}$, and $9(26 \%)$ were nonslow walkers. Among 37 patients who did not reach the primary outcome, $13(35 \%)$ were slow walkers and 24 $(65 \%)$ were non-slow walkers. The 6 months rate of death or readmission was $66 \%(25 / 38 ; 95 \%$ CI $49 \%$ to 


\begin{tabular}{|c|c|c|c|}
\hline $\begin{array}{l}\text { Patients } \\
\text { characteristics }\end{array}$ & $\begin{array}{l}\text { Slow } \\
\text { walkers } \\
(n=38)\end{array}$ & $\begin{array}{l}\text { Non-slow } \\
\text { walkers } \\
(n=33)\end{array}$ & $P$ value \\
\hline Age, year (SD) & $70.6(8.9)$ & $65.3(9.9)$ & 0.02 \\
\hline Male gender, n (\%) & $15(40)$ & $22(67)$ & 0.03 \\
\hline $\mathrm{BMI}, \mathrm{kg} / \mathrm{m}^{2}(\mathrm{SD})$ & $34.7(9.9)$ & $30.5(10.7)$ & 0.09 \\
\hline Heart failure, $n(\%)$ & $20(54.1)$ & $8(24.2)$ & 0.03 \\
\hline COPD, n (\%) & $23(61)$ & $27(81)$ & 0.05 \\
\hline $\begin{array}{l}\mathrm{FEV}_{1}, \% \text { of } \\
\text { predicted (SD) }\end{array}$ & $53.1(22.3)$ & $45.9(14.6)$ & 0.12 \\
\hline $\mathrm{PaCO}_{2}, \mathrm{kPa}(\mathrm{SD})$ & $8.9(1.6)$ & $9.3(3.4)$ & 0.6 \\
\hline HMV, n (\%) & $16(42)$ & $16(32)$ & 0.63 \\
\hline OHS, n (\%) & $13(37)$ & $6(18)$ & 0.08 \\
\hline $\begin{array}{l}\text { LOS in ICU, day } \\
\text { (SD) }\end{array}$ & $3.4(3.3)$ & $3.8(3.9)$ & 0.6 \\
\hline 6MWD, metre (SD) & $120(88)$ & $386(91)$ & $<0.01$ \\
\hline
\end{tabular}

BMI, body mass index; COPD, chronic obstructive pulmonary disease; FEV1, forced expiratory volume in one second; HMV, home mechanical ventilation; ICU, intensive care unit; LOS, length of stay; 6MWD, 6 min walk distance; OHS, obesity-hypoventilation syndrome; $\mathrm{PaCO} 2$, arterial carbon dioxide pressure.

$80 \%)$ among slow walkers and 27\% (9/33; 95\% CI 13\% to $46 \%)$ among non-slow walkers $(\mathrm{p}=0.002$; figure 1$)$. In univariate analysis, gait speed, treated as a continuous variable, was associated with the primary outcome (HR 0.41; $95 \%$ CI 0.19 to 0.90 ), while age, gender, BMI, heart failure, $\mathrm{FEV}_{1}$ and being discharged with $\mathrm{HMV}$ were not (table 2). In the multivariate model including age, gender, BMI, $\mathrm{FEV}_{1}$, heart failure and HMV, gait speed remained the only variable associated with death or readmission (multivariate HR: $0.35,95 \%$ CI 0.14 to 0.88 , $\mathrm{p}=0.025$; table 2$)$.

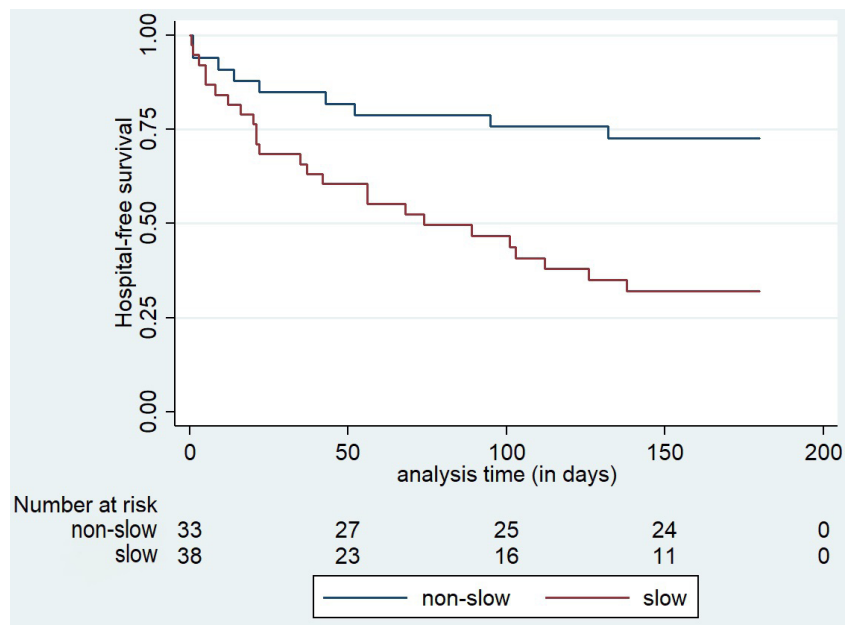

Figure 1 Death or readmission during follow-up among slow and non-slow walkers.

\section{DISCUSSION}

In this secondary analysis of a prospective cohort study, gait speed was significantly associated with death or hospital readmission among AHRF survivors. The likelihood to reach the outcome decreased by about three times for every $1 \mathrm{~m} / \mathrm{s}$ increase in gait speed (multivariate HR: 0.35). By contrast, age, $\mathrm{FEV}_{1}$, heart failure, BMI and discharge with home NIV were not associated with 6 months death or readmission.

These results suggest that gait speed, as a measure of functional status, might be of importance for risk stratification in patients surviving AHRF. Our results are consistent with previous observations reporting the prognostic importance of gait speed in other settings. ${ }^{1416}$ In a pooled analysis of 9 cohort studies including 34485 older adults aged 65 years or older, Studenski et al reported an association between gait speed and 10-year survival among older patients with an overall HR for mortality of 0.88 ( 0.87 to 0.90), after adjusting for gender, BMI, smoking or medical history. The association between gait speed and mortality or readmission was also reported among patients with chronic respiratory diseases, ${ }^{15}$ chronic heart failure ${ }^{17}$ and patients undergoing post cardiac rehabilitation. ${ }^{18}$ In a cohort of 130 patients with idiopathic pulmonary fibrosis, Nolan et al also reported a significant association between gait speed and all-cause mortality or hospital admission. Multivariate models including gait speed had better discrimination for predicting mortality than a clinical tool to predict idiopathic pulmonary fibrosis outcome combining gender, age, forced vital capacity and diffuse capacity of the lung for carbon monoxide. ${ }^{15}$ Moreover, gait speed is a consistent predictor of mortality among ambulatory patients with COPD and elderly patients with COPD admitted to the hospital for an acute exacerbation. ${ }^{19} 20$

The prognostic importance of gait speed illustrates the importance of functional parameters among patients with respiratory failure. Although previous studies usually calculated gait speed using a 4-metre gait speed (4MGS), the proposed cut-off values were very similar to our with proposed values between 0.7 and $1 \mathrm{~m} / \mathrm{s}^{14} 2122$ The correlation between 4MGS and 6MWT and functional capacity has been demonstrated among patients with COPD and other causes of respiratory failure. ${ }^{23} 24$ Measure of gait speed using very short distances such as the $4 \mathrm{~m}$ gait speed or the timed up and go test is gaining widespread popularity because it can be performed in very frail patients as well as at the doctor's office. ${ }^{25}$ Gait speed is an integrative measure including respiratory and cardiac capacity, cognitive status, motor function, coordination, sensory perception and nutritional status. ${ }^{26}$ Moreover, decreased mobility may further result in reduced physical activity and deconditioning which may lead to decreased survival. ${ }^{27}$ The concept of frailty, a progressive decline in multiorgan function, has gained popularity among geriatricians and respiratory physicians. ${ }^{28-30}$ Frailty not only represents an important prognostic predictor, but may also represent a target for 


\begin{tabular}{|c|c|c|c|c|}
\hline Predictor & Univariate HR $(95 \% \mathrm{Cl})$ & $P$ value & Multivariate HR $(95 \% \mathrm{Cl})$ & $P$ value \\
\hline Gait speed & 0.41 (0.19 to 0.90$)$ & 0.025 & 0.35 (0.14 to 0.88$)$ & 0.025 \\
\hline Age & 1.01 (0.99 to 1.05$)$ & 0.26 & $1.0(0.95$ to 1.03$)$ & 0.88 \\
\hline Male gender & 0.89 (0.46 to 1.07$)$ & 0.71 & 0.98 (0.44 to 2.1$)$ & 0.96 \\
\hline BMI & 1.0 (0.95 to 1.02$)$ & 0.46 & 0.97 (0.92 to 1.02$)$ & 0.24 \\
\hline Heart failure & 1.53 (0.8 to 2.96$)$ & 0.20 & 1.35 (0.63 to 2.9$)$ & 0.78 \\
\hline $\mathrm{FEV}_{1}$ & $1.0(0.98$ to 1.01$)$ & 0.65 & 0.99 (0.97 to 1.02$)$ & 0.80 \\
\hline HMV & $1.1(0.56$ to 2.1$)$ & 0.80 & 1.26 (0.54 to 2.9$)$ & 0.58 \\
\hline
\end{tabular}

$\mathrm{BMI}$, body mass index; FEV1, forced expiratory volume in $1 \mathrm{~s} ; \mathrm{HMV}$, home mechanical ventilation.

multidimensional interventions. Multimodal and pluriprofessional interventions aiming to restore functional capacity such as integrated care pathways have been developed for patients with airway disease and pulmonary rehabilitation programmes have been shown to reduce hospital readmission or death after COPD exacerbation. ${ }^{31-35}$ Therefore, risk stratification based on simple functional parameters such as gait speed might contribute to better identify patients who would benefit from these interventions.

Our study has several strengths. First, we included consecutive patients with various aetiologies of respiratory failure. Second, predictive variables and outcome assessment were prospectively recorded and outcome assessors were blinded for the results of predictive variables. Gait speed assessment was standardised in order to assure its reproducibility. Our study has also several limitations. First, we used a convenient sample size limiting the power of our measures of association and the precision of the strength of association estimates and preventing us to separately analyse death and readmission. This could contribute to the absence of significant association between traditional variables and outcome. Moreover, we included all prespecified clinically relevant variables in our multivariate model which resulted in a non-parsimonious model which has been reported to increase the risk of spurious findings. However, the rate of the primary outcome was sufficient to obtain a highly significant association between gait speed and death or readmission. Second, patients were allowed to stop during the $6 \mathrm{MWT}$, but the duration of the stop was not recorded. In these cases, the gait speed might have been underestimated, especially among the most affected patients. Moreover, oxygen therapy during 6MWT was not recorded. Finally, given the observational nature of this study, further research is required to evaluate if improved prognostic assessment of patients surviving AHRF would improve their management and prognosis.

\section{CONCLUSION}

Our data suggest that gait speed, as simple functional parameter, is associated with death or hospital readmission in patients surviving AHRF. Improved risk stratification of these patients might contribute to better individualise therapeutic interventions and better identify patients who would benefit from rehabilitation or integrated care programmes.

Contributors GK, CM and DA conceived and designed the study; drafted the manuscript. DA conceived the original study and analysed the data. GA and DZ participated to the study by critically reviewing the manuscript. All authors approved the final version.

Funding The study was supported by the "Ligue Pulmonaire Genevoise" and by the research Fund of the Department of Internal Medicine of the University Hospital and Faculty of Medicine of Geneva.

Competing interests None declared.

Patient and public involvement Patients and/or the public were not involved in the design, or conduct, or reporting, or dissemination plans of this research.

Patient consent for publication Not required.

Ethics approval The study protocol was approved by the University of Geneva institutional review board (\#11-238) and registered at www.clinicaltrials.gov (identifier NCT02111876).

Provenance and peer review Not commissioned; externally peer reviewed.

Data availability statement Data are available upon reasonable request.

Open access This is an open access article distributed in accordance with the Creative Commons Attribution Non Commercial (CC BY-NC 4.0) license, which permits others to distribute, remix, adapt, build upon this work non-commercially, and license their derivative works on different terms, provided the original work is properly cited, appropriate credit is given, any changes made indicated, and the use is non-commercial. See: http://creativecommons.org/licenses/by-nc/4.0/.

\section{REFERENCES}

1 Brochard L, Mancebo J, Wysocki M, et al. Noninvasive ventilation for acute exacerbations of chronic obstructive pulmonary disease. $N$ Engl J Med 1995;333:817-22.

2 Kramer N, Meyer TJ, Meharg J, et al. Randomized, prospective trial of noninvasive positive pressure ventilation in acute respiratory failure. Am J Respir Crit Care Med 1995;151:1799-806.

3 Carlucci A, Delmastro M, Rubini F, et al. Changes in the practice of non-invasive ventilation in treating COPD patients over 8 years. Intensive Care Med 2003;29:419-25.

4 Benhamou D, Girault C, Faure C, et al. Nasal mask ventilation in acute respiratory failure. Experience in elderly patients. Chest 1992;102:912-7.

5 Suissa S, Dell'Aniello S, Ernst P. Long-term natural history of chronic obstructive pulmonary disease: severe exacerbations and mortality. Thorax 2012;67:957-63.

6 Vitacca M, Clini E, Rubini F, et al. Non-invasive mechanical ventilation in severe chronic obstructive lung disease and acute respiratory failure: short- and long-term prognosis. Intensive Care Med 1996;22:94-100.

7 Confalonieri M, Parigi P, Scartabellati A, et al. Noninvasive mechanical ventilation improves the immediate and long-term outcome of COPD patients with acute respiratory failure. Eur Respir J 1996;9:422-30. 
8 Chu CM, Chan VL, Lin AWN, et al. Readmission rates and life threatening events in COPD survivors treated with non-invasive ventilation for acute hypercapnic respiratory failure. Thorax 2004;59:1020-5

9 Almagro P, Soriano JB, Cabrera FJ, et al. Short- and medium-term prognosis in patients hospitalized for COPD exacerbation: the CODEX index. Chest 2014;145:972-80.

10 Soler-Cataluña JJ, Martínez-García MA, Sánchez LS, et al. Severe exacerbations and bode index: two independent risk factors for death in male COPD patients. Respir Med 2009;103:692-9.

11 Adler D, Pépin J-L, Dupuis-Lozeron E, et al. Comorbidities and subgroups of patients surviving severe acute hypercapnic respiratory failure in the intensive care unit. Am J Respir Crit Care Med 2017;196:200-7.

12 Jones SE, Maddocks M, Kon SSC, et al. Sarcopenia in COPD: prevalence, clinical correlates and response to pulmonary rehabilitation. Thorax 2015;70:213-8.

13 Mittal N, Raj R, Islam EA, et al. The frequency of frailty in ambulatory patients with chronic lung diseases. J Prim Care Community Health 2016;7:10-15.

14 Studenski S, Perera S, Patel K, et al. Gait speed and survival in older adults. JAMA 2011;305:50-8.

15 Nolan CM, Maddocks M, Maher TM, et al. Gait speed and prognosis in patients with idiopathic pulmonary fibrosis: a prospective cohort study. Eur Respir J 2019;53. doi:10.1183/13993003.01186-2018

16 Kahlon S, Pederson J, Majumdar SR, et al. Association between frailty and 30-day outcomes after discharge from hospital. CMAJ 2015;187:799-804.

17 Tabata M, Shimizu R, Kamekawa D, et al. Six-minute walk distance is an independent predictor of hospital readmission in patients with chronic heart failure. Int Heart J 2014;55:331-6.

18 La Rovere MT, Pinna GD, Maestri R, et al. The 6-minute walking test and all-cause mortality in patients undergoing a post-cardiac surgery rehabilitation program. Eur J Prev Cardiol 2015;22:20-6.

19 Kon SSC, Patel MS, Canavan JL, et al. Reliability and validity of 4-metre gait speed in COPD. Eur Respir J 2013;42:333-40.

20 Kon SSC, Jones SE, Schofield SJ, et al. Gait speed and readmission following hospitalisation for acute exacerbations of COPD: a prospective study. Thorax 2015;70:1131-7.

21 Studenski S, Perera S, Wallace D, et al. Physical performance measures in the clinical setting. J Am Geriatr Soc 2003;51:314-22.

22 Cesari M, Kritchevsky SB, Penninx BWHJ, et al. Prognostic value of usual gait speed in well-functioning older people--results from the Health, Aging and Body Composition Study. J Am Geriatr Soc 2005;53:1675-80.
23 DePew ZS, Karpman C, Novotny PJ, et al. Correlations between gait speed, 6-minute walk distance, physical activity, and selfefficacy in patients with severe chronic lung disease. Respir Care 2013;58:2113-9.

24 Ilgin D, Ozalevli S, Kilinc O, et al. Gait speed as a functional capacity indicator in patients with chronic obstructive pulmonary disease. Ann Thorac Med 2011;6:141-6.

25 Podsiadlo D, Richardson S. The timed "Up \& Go": a test of basic functional mobility for frail elderly persons. J Am Geriatr Soc 1991;39:142-8.

26 Morlino P, Balbi B, Guglielmetti S, et al. Gait abnormalities of COPD are not directly related to respiratory function. Gait Posture 2017;58:352-7.

27 Cesari M, Kritchevsky SB, Newman AB, et al. Added value of physical performance measures in predicting adverse health-related events: results from the health, aging and body composition study. $J$ Am Geriatr Soc 2009;57:251-9.

28 Bousquet J, Dinh-Xuan AT, Similowski T, et al. Should we use gait speed in COPD, FEV1 in frailty and dyspnoea in both? Eur Respir J 2016;48:315-9.

29 Vaz Fragoso CA, Enright PL, McAvay G, et al. Frailty and respiratory impairment in older persons. Am J Med 2012;125:79-86.

30 Valenza MC, Torres-Sánchez I, Cabrera-Martos I, et al. Physical activity as a predictor of absence of frailty in subjects with stable COPD and COPD exacerbation. Respir Care 2016;61:212-9.

31 European Innovation Partnership on Active and Healthy Ageing, Action Plan B3, Mechanisms of the Development of Allergy, WP 10, Global Alliance against Chronic Respiratory Diseases, et al. Integrated care pathways for airway diseases (AIRWAYS-ICPS). Eur Respir J 2014;44:304-23.

32 Bousquet J, Barbara C, Bateman E, et al. AIRWAYS-ICPs (European innovation partnership on active and healthy ageing) from concept to implementation. Eur Respir J 2016;47:1028-33.

33 Puhan MA, Gimeno-Santos E, Cates CJ, et al. Pulmonary rehabilitation following exacerbations of chronic obstructive pulmonary disease. Cochrane Database Syst Rev 2016;12:CD005305.

34 Beauchamp MK, Evans R, Janaudis-Ferreira T, et al. Systematic review of supervised exercise programs after pulmonary rehabilitation in individuals with COPD. Chest 2013;144:1124-33.

35 Richardson CR, Franklin B, Moy ML, et al. Advances in rehabilitation for chronic diseases: improving health outcomes and function. BMJ 2019;365:I2191. 